\title{
Portraits of primary school pre-service teachers at a South African university: Implications for nuanced student support
}

\section{Sarita Ramsaroop}

Department of Childhood Education, University of Johannesburg, Johannesburg, South Africa saritaram@uj.ac.za

https://orcid.org/0000-0003-2437-4229

\section{Nadine Petersen}

Department of Childhood Education, University of Johannesburg, Johannesburg, South Africa nadinep@uj.ac.za

https://orcid.org/0000-0001-5283-1074

(Received: 26 January 2020; accepted: 10 August 2020)

\begin{abstract}
In this article, we report on a study of two South African primary school teacher education cohorts undertaken to investigate and understand their readiness to succeed in higher education and to plan support accordingly. Using the methodology of portraiture, we generated data from a combination of student questionnaires and examination results. Qualitative content analysis enabled the construction of six personas and three main themes. The portraits helped with an understanding of the complexity of the themes, in particular with how an identification of both the malleable and non-malleable elements affecting students' lives could inform and shape interventions for successful transition into university. More specifically, the dominance of particular characteristics in the personas provided information about which student groups required the most psychosocial and academic support and where it was required. The portraits also helped us to gauge the value of existing firstyear initiatives, such as the educational excursion, for promoting student enculturation and in overcoming their initial anxieties and preconceptions. We argue for more nuanced information about students to inform a multipronged approach to student support that may extend much longer than teacher educators anticipate.
\end{abstract}

Keywords: teacher education; primary school; first-generation students; portraiture; student personas; higher education support

\section{Introduction}

South African higher education researchers are aware that increasing access for previously disadvantaged students has not necessarily translated into increased academic success or 
throughput for the majority. In the scarce-skills area of primary school teacher education we have some idea about what draws students into these programmes, and we have seen a steady increase in the number of students opting for this specialisation. However, despite increased access to higher education and financial support for students since 2018, as a sector we continue to struggle with student throughput and success (Council on Higher Education, 2013; Dhunpath \& Subbaye, 2018). In seeking to tailor an institutional response to student success and throughput, we drew on the growing body of research on support interventions by higher education.

At the institution at which we conducted this study, university-wide surveys have provided broad insights into the struggles of incoming students as van Zyl (2016) has noted, showing that those from the lowest socio-economic groups (mainly African) struggle with funding, a lack of parental support, and poor academic preparation. Informed by Conley's (2017) readiness theory we were of the view that we needed to look beyond generalisations and adopt a process of collecting information that provided a nuanced understanding of the needs of our specific students. In this paper we describe how we used portraiture methodology to generate data that enabled the construction of six first-year student teacher personas to be read in conjunction with reports of student struggles to inform a tailored support programme. We describe how this unfolded and argue for the value of portraiture research in capturing the complexity of first-year student struggles so as to inform interventions for support in primary school teacher education.

\section{Factors impacting student success at university}

Conley's (2017, p. 12) differentiation between students" "eligibility to be admitted" and "readiness to succeed", and research on the struggles of first-generation students frames the parameters of the literature review. An eligibility model, common to many higher education institutions including South African universities, applies a set of programmatic and institutional criteria for student admission. A danger of the eligibility model is that student gaps and shortfalls that affect success are not always adequately considered. In contrast, a readiness to succeed model takes into consideration both malleable elements, such as the development of particular skills to succeed, and non-malleable ones, such as socio-economic status. It also draws on important but often disregarded information from multiple sources (Conley, 2017) that could assist in transitioning students successfully from school to university. This can include, for instance, students' motivations for pursuing a particular career, their ability to self-regulate, and their familiarity with technology. In our view, the latter model is more suitable to South African higher education, particularly given the growing emphasis on narrowing the gap between access, equity, and success for all students.

South African researchers like Mdepa and Tshiwula (2012) and Nyamupangedengu (2017) and their international counterparts such as Nagaoka et al. (2013) and Sibomana (2016) have revealed that students often come from schooling backgrounds that have not enabled them to develop the requisite academic skills and orientation required for success at university. Academic writing, mathematics, and other subject content knowledge are three areas of 
importance for primary school teacher education. However, much research (see Leibowitz, 2004; Pineteh, 2014) attests to the struggles of students in these areas. There is also a swathe of research that captures first-year students' struggles with operating in a new environment, especially for those described as first-generation students.

Typically, as Barry et al., (2009) have noted, the first in their family to attend a higher education institution are known as first-generation students. They have been described by Richardson and Skinner (1992, p. 41) as "uncertain climbers" who require concerted support to help them develop more control and responsibility over their transition from high school to university (see, too, Stebleton \& Soria, 2013). In South Africa, most of these students are from previously disadvantaged race groups, and researchers have tended to ascribe their lack of progress to poorly developed academic English language use as Bui (2002) has noted. The issue of language is, however, not clear-cut. Critical language scholars such as Rudwich (2018) have argued that the rhetoric of language policies at South African universities gives rise to contested identity politics, with its own repercussions for students. Others, such as Mwaniki et al. (2018), Motinyane (2018), and Mayaba (2018), in arguing for decolonisation in higher education, have addressed the need to transform institutional cultures and language policies at university. They are of the view that universities do not sufficiently address the issue of the multiplicity of languages in South Africa. Here, Madadzhe (2019) has contended that decolonisation projects should move beyond simply including a focus on African issues and make greater use of African languages in higher education programmes at both undergraduate and postgraduate level. Heleta (2016) concurred. There are some examples of this being enforced in undergraduate programmes at universities such as KwaZulu-Natal, Rhodes, Limpopo, and UNISA, and at postgraduate level at the Universities of Pretoria and Venda.

Putting aside the politics of English as a language of instruction, there have also been studies that have confirmed that while most students, regardless of their home language, have reasonable basic interpersonal communicative skills (BICS) in English, when they enter university (see, for instance, van der Merwe, 2018), many have low core academic language proficiency (CALP), as Cummins (2000) put it. A lack of CALP as a specialized, abstract, decontextualized language of formal education (Cummins, 2000), with complex syntax, vocabulary and discourse practices seems to be one of the main reasons students struggle with progress in higher education (Civan \& Coskun, 2016; Seligman, 2008; van der Merwe, 2018). This impacts negatively on students' ability to understand their academic content and convey their ideas.

Other factors that influence assimilation into university and, consequently, student success include first-year students' vulnerability (McKay et al., 2018) and their need to develop social networks to transition successfully to university (Kantanis, 2000). This is especially difficult for those from poor socio-economic groups since they struggle to make friends as McLoughlin (2012) and van Zyl (2016) have observed. An absence of social networks can lead to issues with self-confidence, feelings of isolation, university life in general (Kantanis, 2000), and an increasing need for psychological and career support (McKay et al., 2018). 
Other factors include inadequate study skills (Stebleton \& Soria, 2013) and a need to supplement their income (Jehangir, 2010).

Using a readiness to succeed approach requires understanding among higher education staff of the complex web of institutional, academic, and social barriers that impact on student success and, thus, the resources required to tailor interventions to address them (Murphy et al., 2018). This is possible only with the right kind of data to inform responsive and nuanced decision-making.

\section{Methodology}

In order to gather detailed information, we used portraiture research and posed the following question:

How can research portraits be used to capture the complexity of first-year students' struggles in order to inform interventions for support in primary school teacher education?

Following Lawrence-Lightfoot (2005) and Lawrence-Lightfoot and Davis (1997), our use of research portraits or portraiture stemmed from a desire to capture the dominance of particular characteristics along with narrative descriptors. We used a cohort of 237 students as the basis for creating personas that would allow us to engage "creatively and holistically with research participant data" (Golsteijn \& Wright, 2013, p. 299). Research portraits (or portraiture) have long been used as a verbal rather than an artistic medium in qualitative research to reflect participants' subjective identities and describe what shapes them and their aspirations along with views of the factors that impact their lives. Within portraiture research, personas feature as "composite fictional characters" that are constructed to "embody multiple users" unique characteristics." Such personas serve as "character descriptions" and are the "archetypal representation of an actual user group whose members share similar needs and goals." In other words, they serve as "placeholders for individuals" (Golsteijn \& Wright, 2013, p. 301).

Gathering data for the portraits began with first-year students' responses to two qualitative questionnaires, one of which was conducted at the beginning of the academic year, asking about students' backgrounds, family expectations, fears, and struggles. A second questionnaire captured their progress after the first six months at university. We measured in part their June examination results, their impressions of the value of the university's first-year experience interventions, and their struggles in the first six months at university.

In analysing the data, we followed a two-step process. In phase one, using procedures associated with content analysis (see Patton, 2002) and descriptive statistics (Henning et al., 2004) we crafted six student portraits. Prevalence in the data helped identify the most meaningful indicators for differentiating between the personas, with each representing a set of characteristics common to a number of individuals from the first-year primary school teacher education cohort $(n=237)$. These included students' demographic classification, their socio-economic situation, their geographic home background/origins, any financial support 
for university studies and current living conditions, home language, whether or not they were first-generation students, family expectations, their first experiences of social integration at the institution, and current challenges. In the second stage of data analysis we looked for the prevalence of particular items and identified generalised patterns across the data, including how these featured in each of the portraits. From this process, we constructed three themes.

\section{Presentation of findings}

In this section, we present the six personas before moving on to a description of the three main themes. While the generalised demographic featured as the basis for each of the personas may be familiar to South African higher education teachers, our interest was in how dominant each persona was in the cohorts and how they could be differentiated from each other in order for us to better understand the three themes. Pseudonyms have been used to preserve anonymity.

The first persona, Nkososana, represents $29.5 \%(n=70)$ of the first-year group in the two teacher education programmes. A female student between the ages of 17 and 22, she was from an impoverished rural area. The second persona, Lerumo, was a male student from a rural background, who represented $4.6 \%(n=11)$ of the cohort. Of the 11,1 was in the foundation phase and 10 in the intermediate phase programme. The third persona, Zunaid, represented $0.8 \%(\mathrm{n}=2)$ of male students who came from a middle-class urban background, and the fourth was Thabo, an urban male who depicted $4.2 \%(n=10)$ of first-year students from a low socio-economic background. The fifth persona, Laura, was an urban female student from a middle-class background who represented $18.1 \%(n=43)$ of the first-year group. The sixth persona was the impoverished urbanite, Lydia, who represented $42.6 \%$ $(\mathrm{n}=101)$ of female students.

Theme 1: Moving from being scared and alone to making friends: The importance of first-year experience interventions

Almost all the data generated at the start of the year provided evidence of students' feelings of uncertainty, loneliness, and isolation associated with leaving home and entering a strange environment. Nkosasana described being overwhelmed since she did not know anyone and was afraid that her impoverished background and inability to communicate with new people would leave her feeling isolated. She believed that "all university students are from rich families." She said, "I thought my poor background would make people not associate with me." Her lack of confidence was also a problem. Describing herself as "a very shy person ... who finds interacting with people very intimidating", she was of the view that she would "not make new friends" or "be accepted in groups." Lerumo, Thabo, Lydia, and Laura expressed similar fears, citing reasons such as their unease with "approach(ing) strangers, "being shy" and "quiet" and thus "finding it difficult [to meet] new people or [make] conversations with them." Many feared that "some people would be rude when [we] approach them." The exception was Zunaid, who was looking forward to meeting new personalities but who expressed some reservations about negative influences. 
All students credited the first-year experience interventions, and, in particular, a three-day educational excursion, as valuable in helping them move from feeling uncertain and lonely to being welcomed and accepted. For example, Lydia and Nkosasana described how the excursion "broke the tension and ice between [them] and a lot of students [they] engaged with." Student descriptions of the reasons for this included the "very informal and relaxed environment" of the excursion, the "group activities that involved different cultures and races" as well as being placed in "groups of twelve randomly to share a dorm." The students pointed out how the excursion helped them address their preconceived notions about other races and cultural groups. Lerumo said, "I never thought in my life I would share a meal with other races, we isolated in class" while Thabo said. "I was not used to people of other cultures, at excursion I realised they are friendly" and Zunaid added, "We got to know each other through group work and sharing rooms." Laura described how she found it difficult initially to communicate with her peers because she "doesn't understand most [African] languages" but found that the excursion activities provided opportunities for her and other students "to learn about each other's cultures while interacting." Data generated six months into the academic year showed that most students were no longer as uncertain or lonely as they had been at the beginning of their university studies. Drawing on student responses we were pleased to note that the current first-year educational experience contributed substantially to helping them overcome their initial anxieties and preconceptions.

\section{Theme 2: Poverty and hunger drive students' expectations of academic success}

The data confirmed that a large percentage of students come from poverty-stricken families. The responses of Nkososana, Lerumo, Thabo, and Lydia, were peppered with words such as "poor", "unstable" or "less privileged" as they described their working-class backgrounds and financial constraints. Nkososana and Lydia's group had more often than not been raised and supported by a single mother, grandmother, aunts, an extended family, or siblings. Lerumo and Thabo also described similar domestic circumstances using similar explanations that included being "raised by our mother. Father passed away" and "supported by mum, dad is unemployed, an aunt helps out." Of the students, $75 \%$ (n=177 of the 237) reported reliance on external sources of sponsorship or bursaries to finance their education.

Data from the beginning of the academic year showed that being the first in the family to study at university placed students under excessive pressure to succeed academically. The students were acutely aware of the expectations of their success and this created one of many pressures for $85.5 \%$ of the first-year mainly African students. Their academic success was key to helping their extended families escape poverty. Nkososana explained, "I am expected to study hard and complete my degree in four years so that I can return home to support my family." Similarly, Lydia indicated that "the family cannot afford to pay for my fees if I fail or if I lose my bursary." She was often reminded that "they [the family network] had to take out their last money" to support her. The financial background of Thabo's group, who constituted $4.2 \%$ of the students, and Lerumo's, (4.6\%), were similar. They, too, described being "raised by a single parent (mother)" and as "struggling financially." They were expected to "do well" in their studies so that they could support their families, and "come 
home with [an] education degree and bring change at home." As a result, six months into the academic programme these students reported struggling with the balance "between attending classes and tutorials and leading an independent life." However, Laura, although also a firstgeneration student, did not experience the same kinds of pressure. She, like Zunaid, was "focused and do[ing] everything to the best of [her] ability" and "being responsible and making use of this opportunity" in order to graduate and "get a stable job."

It is thus not surprising that failure was one of the greatest fears of Thabo, Lerumo, Nksosana, and Lydia. Lerumo and Lydia were most afraid of "not coping with workload, and ... not getting a bursary and withdrawing" while Nkososana and Thabo feared "not being funded by financial aid and going back home" and spoke of "the fear of failing a module . . . as a year will be added." In addition, some students were afraid that the loss of a bursary would impact their ability to meet basic needs. Lerumo said, "I would not be able to buy myself food as I am responsible for any financial need I have." Six months into the year, lack of funding became a reality for many. For example, Nkososana explained her dilemma: "I have been struggling with school fees money as there is no one working at home" and "I was declined Funza' ${ }^{1}$ unexpectedly."

In contrast, neither Zunaid nor Laura experienced the financial struggles of the other personas. They come from middle class families with two parents who support them. These were outliers in the data, with Zunaid representing $0.8 \%$ of the student cohort $(n=2)$ and Laura constituting $18.1 \%(\mathrm{n}=43)$.

\section{Theme 3: "I don't understand what the lecturers are saying": How can I learn?}

For Nkososana, Lerumo, Thabo, and Lydia, the spectre of studying in English, which is sometimes a second but also often a third or fourth language, was a major strain. They all felt that they were far behind the expected levels of verbal communication in English. Six months into the academic year, many reported struggling and commented, "It has been a great challenge since I don't really understand the language." "[T]hey (lecturers) using big English words." "[I]t is difficult to comprehend some of the content." Consequently, these students had barely passed (41.5\%) English, with $19 \%$ failing the subject. Since this is a compulsory major this failure automatically extended their studies by six to twelve months.

In addition, the lack of English proficiency had impacted on their learning in other modules. For example, Nkososana, Lerumo, and Thabo complained that the "exam was difficult to understand and cost me marks ... [and] it [the lack of English proficiency] has impacted me badly especially when writing tests and exams." Lydia said, "Sometimes it's a challenge to complete given assignments." The level of their "threshold English" (Seligmann, 2008, p. 45) meant that many also struggled with learning the course content of the teacher education programme properly, and some (30\%) failed one or two modules, and sometimes even more (21\%). This not only retarded their progress but also placed undue additional financial and psychological pressure on the students. However, it was not only English second language 
speakers who struggled. Zunaid and Laura, as English first language speakers who claimed confidence with, and competence in, the language showed only slightly better results than their peers in mid-year examinations.

Another subject area with which all students in this study reported struggling was mathematics. The reasons they provided ranged from "Mathematics is difficult for me" and "I have been struggling with understanding content" to "grasping particular concepts." In addition, students found difficulty "with understanding how to approach assignments" and "moving from spoon-feeding in high school" to "working independently." The students' midyear examination results attested to this. Studies with a first-year cohort in the same programmes showed a $37 \%$ baseline for primary school mathematics content knowledge (Fonseca \& Petersen, 2015). Student results in the last five years show similar patterns.

Another area with which most of the students report having struggled was the use of technology. Concerns raised by Nkososana, Lerumo, Thabo, and Lydia included difficulty in learning how to use a computer "to type assignments", "to research assignments", and "to submit online assignments." It resulted in not only taking more "time to do [their] school work using computers", but students were equally unsure about how the online submissions operated. They seemed not to trust technology, as evidenced in what they said: "The system may give me problems and end up not submitting" and "am unsure about submitting assessments online." Laura and Zunaid were also unsure about "the higher levels of technology" required at university and explained that they had "little understanding of online systems."

\section{Discussion}

The first-year pre-service teacher participants in this study, like many other higher education students, were in a liminal phase (Turner, 1987) and as Turner (1977, p. 37) put it, "betwixt and between" being school learners and becoming university students. This is an intense experience since it necessitates a break from the familiar past, as well as an adjustment to a different environment in which they need to learn, as university students, a new way of working over a concentrated period. Their eligibility for admission had enabled them to bridge the first hurdle of entry to higher education. It did not, however, guarantee their success. Working with Conley's (2017) readiness to succeed model we realised that we needed much more information about the complexity of the issues first-year students face, in order to plan nuanced and targeted interventions. The construction of six portraits enabled us to identify the malleable elements, such as the lack of academic writing skills, and the nonmalleable ones, such as the particular socio-economic circumstances of students, required to inform and shape interventions to help students make the transition successfully.

As is typical in such an adjustment period we were not surprised that the majority of students described their early days at university as lonely and uncertain. What was new to us, though, was the extent of their social anxiety and perceived inferiority that arose given their socioeconomic status. The differences in the responses of Lerumo, Thabo, and Lydia, who hailed 
from impoverished backgrounds, to that of middle class Zunaid and Laura, are, so to speak, tangible. Literature from a social psychological perspective (see Manstead 2018) contends that social class and socio-economic status have a great influence on self-concept (Stephens et al., 2014) and give rise to particular "patterns of thinking, feeling and acting" (p. 611). The mismatch between someone's background and their being a university student (see also Reay et al., 2009) is most evident in the comment by Nkososana, who thought "universities were for rich people." For first generation students from lower socio-economic status backgrounds, Kruas et al. (2017) have argued that subjective social class is linked to and affects social behaviour. This understanding emphasises the importance for us as teacher educators to understand the comments from students such as Lerumo, Thabo, Lydia, and Nkososana who are motivated by a deep psychological need to deal with an external fear, the threat of rejection, and feeling out of place. It also means that interventions must create opportunities for students to build the confidence to address their belief that they have little control over how others react or behave towards them (see, for instance, Kraus et al., 2009). These students need much more support in building resilience than do Laura and Zunaid who are in the minority. It is also an issue about which academic staff need to know and address in their interactions with students so as not to alienate them further, especially when they are struggling.

In this respect, there is value in first-year experience intervention programmes (Harvey et al., 2006; Nelson et al., 2011). These range from one-day sessions to week-long programmes in which students are oriented to the logistical, psychosocial, and academic support available to them. We have both at our institution, along with an extended first-year experience educational excursion in which students and staff move off the university campus into an environmental centre for three days of communal living and learning about themselves and their peers as a starting point to becoming a teacher. We have found that the excursion, with its relaxed atmosphere, informal interactions between students and staff, and the shared accommodation is a key mechanism that works to increase opportunities for social networking as the basis of the establishment of learning communities that will endure (Arends \& Petersen, 2018). Including a curriculum that emphasises social learning (Petersen $\&$ Petker, 2011) and dissects the impact of social injustice and privilege on educational provisioning also helps students to begin to address the effects of race, class, and culture (Batchelor \& Mahomed, forthcoming). Sadly, despite growing up in a democratic, mixed school system, students are not at ease mixing with other races and cultures. Given that Nkososana and Lerumo, as students from rural backgrounds, comprised $34.1 \%$ and Thabo and Lydia who hail from so-called township schools (comprising another 46.8\%), where mixed peer groups at school are unlikely, teacher educators have to create deliberate opportunities for first-year students to confront their perceptions about race, culture, and privilege. However, despite its success at bringing together students, a three-day excursion is woefully inadequate in addressing a lifetime of socially learned behaviour.

The deep-seated nature of many students' lack of social and cultural capital means that universities have to find ways of systematically building psychological resilience that helps students recognise that problems are not threats to avoid but are, rather, challenges they can 
meet (Caricati, 2017; Kraus et al., 2011). As Lephakga (2017, p. 10) has reminded us, the colonial project of apartheid saw not only the "impoverishment of many blacks in South Africa" but also created "a people who are disturbed, exploited and psychologically fearful." Among the interventions advocated in the literature are the creation of a more inclusive culture for students from working-class backgrounds, providing working-class role models, and ensuring that forums exist in which students can express their concerns and interests (Manstead, 2018). We have had some success with class representatives who include student feedback at meetings of formal quality committees and in using clear grievance procedures that do not victimise students who speak up, but we find little research that addresses these issues in the South African teacher education literature. Without such interventions, students may continue to perform below their true potential. Without such interventions, we also risk reinforcing patterns of thinking and action for students from particular social class backgrounds, making it more difficult for them to benefit from educational opportunities, as Manstead (2018) has noted, that would increase their social and economic mobility as well as that of their families.

Given that most of the students in this study feel pressured to graduate and provide support for their extended families (Mkhonto, 2018) sometimes referred to as "black tax" as Mangoma and Wilson-Prangley (2018) indicate in the title of their article (see, too, Webb, 2018) or family responsibility, it behoves us to pay sufficient attention to measures that lead to student retention and success. Students portrayed by the archetypes Nkososana, Lerumo, Thabo, and Lydia are at university mostly because of the financial input of a network of family and friends whose hopes of a better future rest on their success. The expectations of family networks add considerable pressure to students who are already struggling in an alien environment. This is something of which not all teacher educators may be aware, and here the provision of resources, such as on-campus wi-fi, inter-campus transport, subsidized ebooks, and meal support by universities is vital, as are opportunities for students to be employed as paid tutors and research assistants. However, it also needs to extend into other areas of teaching and learning so that lecturers learn pedagogical approaches that build students psychologically as well as embrace inexpensive shoestring educational resources, like using recyclable materials, and approaches to lessen the financial burden.

The students' struggle with English, as well as the need for mathematics and ICT support also require attention. As Howie et al., (2012) have noted, most South African school learners perform poorly on international tests such as the Progress in International Reading Literacy Study (PIRLS), and Southern and Eastern African Consortium for Monitoring Educational Quality (SAQMEC) (see Spaull, 2013). And most school teaching, according to Uccelli et al. (2015), does not concentrate on the teaching of English as an academic language for learning. As a result, teacher educators have to find ways to address the students' acquisition of CALP. In this study all students, regardless of their home language backgrounds, appeared to need explicit instruction on academic language conventions. They also require sufficient time to develop their academic language proficiency before entering the schooling system as teachers so that they, in turn, will be able to teach school learners (van der Merwe, 2018). Similarly, poor mathematics content knowledge has its roots in poor quality school teaching. The South 
African results in the trends in International Mathematics and Science Study (TIMMS) (2011) showed that the average Grade 9 South African child performed at levels at least two to three grades lower. If South Africa does not succeed in producing a sufficient number of well-qualified teachers for the primary school it is likely that literacy and numeracy goals will not be achieved and this will impact negatively on the achievement of learners throughout the schooling years (Green et al., 2011).

As with many institutions, we, too, following Larkin et al., (2016), have recognised the need for supplemental instruction opportunities in the first year. Our once-off support programme in semester 1 of the first year for mathematics resulted in limited improvements in student performance. The literature points to the need for increased support and opportunities for students to engage actively with discussions and tasks as well as help in improving their selfregulated learning strategies so that they are able to assess their abilities and correct conceptual errors (Zimmerman et al., 2011). We found similar issues with ICT orientation since students need, first, to be comfortable users of computers and other forms of technology before we can expect them to learn how to use these as pedagogical tools in teaching and learning. Our programmes emphasise the latter to the detriment of student learning.

We have begun to realise that what is required is a multi-pronged and multifaceted approach that extends beyond the first year to subsequent years of students' study. Some of these include academic support, for instance, in the form of individualised and small group tutorials for students who are not coping (Paiva et al., 2017) along with strategies for building conceptual knowledge, and student tracking and follow-up (Conde et al., 2015). However, it seems that we have not begun to address the assistance students need to cope with how their backgrounds influence the ways in which they construe themselves and how they fit into the university environment. If we are to help students navigate the liminal period of adjustment to university successfully, more emphasis needs to be placed on gaining a national picture of student portraits in teacher education to enable us to plan a system-wide curriculum and offer psychological and social support. The Department of Higher Education and Training (DHET) Strengthening Foundation Phase Teacher Education and Primary School Teacher Education projects are two of the first of these initiatives with teams establishing baseline knowledge in key domains such as English and Mathematics (see, for instance, Fonseca et al., 2018) to enable them to plan interventions. We do not, however, see much research on the latter and are left wondering if it is an area to which teacher education should pay more attention. Our student research portraits, for example, were an attempt to understand this more fully in the context in which we operate.

\section{Conclusion}

In this paper, we presented a portraiture of first-year primary school teacher education students at an urban university in South Africa, encapsulated in six personas. These personas, we argue, are representative of a group's generalized characteristics; they provide insights into who first-year students are, what they struggle with, how dominant the complexity of issues is in a particular group of first-year students and how these can be leveraged to support 
students optimally. This research has shown that first-year students entering teacher education programmes have not only to catch up with content they missed at school level but have also to be re-socialised into thinking differently about how they see themselves interacting with others and succeeding at university. Many of the students come from first generation families with a host of factors, including language, that are likely to impact on their success at university. With these personas in mind, we discussed the consequences for students' enculturation into university studies, with particular implications for pedagogy and curriculum differentiation in the teacher education programme and pointed to how we might create a more inclusive culture for students who struggle to fit in.

These personas provided us with information about which student groups require the most psychosocial and academic support and the particular areas in which such support is required. This research also enabled us to gauge the value of existing first-year initiatives, such as the educational excursion for promoting student enculturation. Ultimately, we have learned that the liminality of the students in this programme may extend well beyond the first three months of university studies. Teacher educators need to be aware that support may be required for much longer than they at first anticipated and in areas that they may not traditionally expect.

\section{References}

Arends, D., \& Petersen N. F. (2018). The role of first-year experience excursion in promoting social integration at university: Student teachers' views. South African Journal of Childhood Education, 8(1), 1-9.

Barry, L. M., Hudley, C., Kelly, M., \& Cho, S. J. (2009). Differences in self-reported disclosure of college experiences by first-generation college student status. Adolescence, 44(173), 55-68.

Batchelor, J., \& Mahomed, M. (forthcoming). Promoting social justice in teacher education through an education excursion. In C. McNaught \& S. Gravett (Eds.), Embedding social justice in teacher education and development in Africa. Routledge.

Bui, K. V. T. (2002). First-generation college students at a four-year university: Background characteristics, reasons for pursuing higher education, and first-year experiences. College Student Journal, 36(1), 3-12.

Caricati, L. (2017). Testing the status-legitimacy hypothesis: A multilevel modeling approach to the perception of legitimacy in income distribution in 36 nations. The Journal of Social Psychology, 157(5), 532-540.

Civan, A., \& Coskun, A. (2016). The effect of the medium of instruction language on the academic success of university students. Educational Sciences: Theory and Practice, 16(6), 1981-2004. 
Conde, M. Á., Hérnandez-García, Á., García-Peñalvo, F. J., \& Séin-Echaluce, M. L. (2015). Exploring student interactions: Learning analytics tools for student tracking. In P. Zaphiris \& A. Ioannou (Eds.), International Conference on Learning and Collaboration Technologies (pp. 50-61). Springer.

Conley, D. T. (2017). The new complexity of readiness for college and careers. In K. L. McClarty, K. D. Mattern \& M. N. Gaertner (Eds.), Preparing Students for College and Careers (pp. 9-22). Routledge.

Council on Higher Education. (2013). A proposal for undergraduate curriculum reform in South Africa: The case for a flexible curriculum structure. Council on Higher Education.

Cummins, J. (2000). Language, power, and pedagogy: Bilingual children in the crossfire (vol. 23). Multilingual Matters.

Dhunpath, R., \& Subbaye, R. (2018). Student success and curriculum reform in postapartheid South Africa. International Journal of Chinese Education, 7(1), 85-106.

Fonseca, K., Maseko, J., \& Roberts, N. (2018). Students' mathematical knowledge in a Bachelor of Education (foundation or intermediate phase) programme. In R. Govender \& K. Junqueira (Eds.), Proceedings of the 24th Annual National Congress of the Association for Mathematics Education of South Africa (pp. 124-139). AMESA.

Fonseca, K., \& Petersen, N. (2015). Online supplementary mathematics tuition in a first-year childhood teacher education programme. South African Journal of Childhood Education, 5(3), 1-9.

Green, W., Parker, D., Deacon, R., \& Hall, G. (2011). Foundation phase teacher provision by public higher education institutions in South Africa. South African Journal of Childhood Education, 1(1), 109-122.

Golsteijn, C., \& Wright, S. (2013, September.) Using narrative research and portraiture to inform design research. In P. Kotzé, G. Marsden, G. Lindgaard, J. Wesson \& M. Winckler (Eds.), IFIP Conference on Human-Computer Interaction (pp. 298-315). Springer.

Harvey, L., Drew, S., \& Smith, M. (2006). The first-year experience: A review of literature for the higher education academy. The Higher Education Academy.

Heleta, S. (2016). Decolonisation of higher education: Dismantling epistemic violence and Eurocentrism in South Africa. Transformation in Higher Education, 1(1), 1-8.

Henning, E., Van Rensburg, W. A., \& Smit, B. (2004). Finding your way in qualitative research. Van Schaik. 
Howie, S. J., Van Staden, S., Tshele, M., Dowse, C., \& Zimmerman, L. (2012). PIRLS 2011: South African children's reading literacy achievement report. Centre for Evaluation and Assessment (CEA).

Jehangir, R. R. (2010). Higher education and first-generation students: Cultivating community, voice, and place for the new majority. Palgrave Macmillan.

Kantanis, T. (2000). The role of social transition in students' adjustment to the first year of university. Journal of Institutional Research, 9(1), 100-110.

Kraus, M. W., Park, J. W., \& Tan, J. J. (2017). Signs of social class: The experience of economic inequality in everyday life. Perspectives on Psychological Science, 12(3), $422-435$.

Kraus, M. W., Piff, P. K., \& Keltner, D. (2009). Social class, sense of control, and social explanation. Journal of personality and social psychology, 97(6), 992-1004.

Kraus, M. W., Piff, P. K., \& Keltner, D. (2011). Social class as culture: The convergence of resources and rank in the social realm. Current Directions in Psychological Science, 20(4), 246-250.

Larkin, K., Rowan, L., Garrick, B., \& Beavis, C. (2016). Student perspectives on first year experience initiatives designed for pre-service teachers in their first weeks of university study. Journal of University Teaching \& Learning Practice, 13(1).

Lawrence-Lightfoot, S. (2005). Reflections on portraiture: A dialogue between art and science. Qualitative Inquiry, 11(1), 3-15.

Lawrence-Lightfoot, S., \& Davis, J. H. (1997). The art and science of portraiture. JosseyBass

Leibowitz, B. (2004). Becoming academically literate in South Africa: Lessons from student accounts for policymakers and educators. Language and Education, 18(1), 35-52.

Lephakga, T. (2017). Colonial institutionalisation of poverty among blacks in South Africa. Studia Historiae Ecclesiasticae, 43(2), 1-15.

Madadzhe, R. N. (2019). Using African languages at universities in South Africa: The struggle continues. Stellenbosch Papers in Linguistics Plus (SPiL Plus), 58, 205-218.

Mangoma, A., \& Wilson-Prangley, A. (2018). Black tax: Understanding the financial transfers of the emerging black middle class. Development Southern Africa, 36(4), 118.

Manstead, A. S. (2018). The psychology of social class: How socioeconomic status impacts thought, feelings, and behaviour. British Journal of Social Psychology, 57(2), 267291. 
Mayaba, N. N. (2018). A reflection on language politics at Nelson Mandela University. Southern African Linguistics and Applied Language Studies, 36(1), 4957.

McKay, T., Naidoo, A., \& Simpson, Z. (2018). Exploring the challenges of first-year student funding: An intra-institutional case study. Journal of Student Affairs in Africa, 6(1), $19-32$.

McLoughlin, P. J. (2012). The transition experiences of high-achieving, low-income undergraduates in an elite college environment. Journal of the First-Year Experience \& Students in Transition, 24(2), 9-32.

Mdepa, W., \& Tshiwula, L. (2012). Student diversity in South African higher education. Widening Participation and Lifelong Learning, 13, 1466-6529.

Mkhonto, S. (2018, April 20). Black tax: A responsibility not a burden. news24.com https:// www.news24.com/MyNews24/black-tax-a-responsibility-not-a-burden-20180419

Motinyane, M. (2018). A textual analysis of the African language expressions used during the\# RhodesMustFall campaign. Southern African Linguistics and Applied Language Studies, 36(1), 37-48.

Murphy, M. C., Kroeper, K. M., \& Ozier, E. M. (2018). Prejudiced places: How contexts shape inequality and how policy can change them. Policy Insights from the Behavioral and Brain Sciences, 5(1), 66-74.

Mwaniki, M., van Reenen, D., \& Makalela, L. (2018). Advanced language politics in South African higher education post\# RhodesMustFall. Southern African Linguistics and Applied Language Studies, 36(1), iii-v.

Nagaoka, J., Farrington, C. A., Roderick, M., Allensworth, E., Keyes, T. S., Johnson, D. W., $\&$ Beechum, N. O. (2013). Readiness for college: The role of non-cognitive factors and context. Voices in Urban Education, 38, 45-52.

Nelson, K., Clarke, J., Kift, S., \& Creagh, T. (2011). Trends in policies, programs and practices in the Australasian first year experience literature 2000-2010. Queensland University of Technology.

Nyamupangedengu, E. (2017). Investigating factors that impact the success of students in a higher education classroom: A case study. Journal of Education, 68, 113-130.

Paiva, R. C., Ferreira, M. S., \& Frade, M. M. (2017). Intelligent tutorial system based on personalized system of instruction to teach or remind mathematical concepts. Journal of Computer Assisted Learning, 33(4), 370-381.

Patton, M. Q. (2002). Qualitative research \& evaluative methods (3rd ed.). SAGE. 
Petersen, N., \& Petker, G. (2011). Foundation phase teaching as a career choice: Building the nation where it is needed. Education as Change, 15, S49-S61.

Pineteh, E. A. (2014). The academic writing challenges of undergraduate students: A South African case study. International Journal of Higher Education, 3(1), 12-22.

Reay, D., Crozier, G., \& Clayton, J. (2009). “Strangers in paradise?” Working-class students in elite universities. Sociology, 43(6), 1103-1121.

Richardson, R., \& Skinner, E. (1992). Helping first-generation minority students achieve degrees. In L. Zwerling \& H. London (Eds.), First-generation students: Confronting the cultural issues (pp. 29-43). Jossey-Bass Inc. Publishers.

Seligmann, J. (2008). Integrating language and subject content in higher education: A pedagogy for course design (Unpublished doctoral dissertation). University of Johannesburg, RSA.

Sibomana, E. (2016). "We know what to say, we know what to write, but we don't know how." The challenges of becoming academically literate in a new linguistic and sociocultural space. Education as Change, 20(2), 123-124.

Spaull, N. (2013). South Africa's education crisis: The quality of education in South Africa 1994-2011. Centre for Development and Enterprise.

Stebleton, M., \& Soria, K. (2013). Breaking down barriers: Academic obstacles of firstgeneration students at research universities. The Learning and Assistance Review, 17(2), 7-19.

Stephens, N. M., Markus, H. R., \& Phillips, L. T. (2014). Social class culture cycles: How three gateway contexts shape selves and fuel inequality. Annual Review of Psychology, 65, 611-634.

Turner, V. (1987). Betwixt and between: The liminal period in rites of passage. In L. C. Mahdi, S. Foster \& M. Little (Eds.), Betwixt \& between: Patterns of masculine and feminine initiation. Open Court.

Uccelli, P., Galloway, E. P., Barr, C. D., Meneses, A., \& Dobbs, C. L. (2015). Beyond vocabulary: Exploring cross-disciplinary academic-language proficiency and its association with reading comprehension. Reading Research Quarterly, 50(3), 337356.

van der Merwe, D. (2018). Aspects of academic language proficiency of intermediate phase teacher education students. South African Journal of Childhood Education, 8(1), 1-9.

van Zyl, A. (2016). The contours of inequality: The links between socio-economic status of students and other variables at the University of Johannesburg. Journal of Student Affairs in Africa, 4(1), 1-16. 
Webb, C. (2018). Asinamali: Aspiration, debt and citizenship in South Africa's \#FeesMustFall protests. Area, 51(4), 627-634.

Zimmerman, B. J., Moylan, A., Hudesman, J., White, N., \& Flugman, B. (2011). Enhancing self-reflection and mathematics achievement of at-risk urban technical college students. Psychological Test and Assessment Modeling, 53(1), 141. 